\title{
The Clinical and Bacteriological Profile of Children with Empyema in a Tertiary Hospital
}

\author{
Sudhakar Hegade', Sandeep Biradar ${ }^{2}$ \\ ${ }^{1}$ Assistant Professor, Department of Pediatrics, VIMS, Ballari, Karnataka, ${ }^{2}$ Pediatrician, General Hospital, Basavakalyana, Karnataka.
}

\section{Abstract}

Background: Empyema thoracis is a condition in which pus and fluid from infected tissue collects in the pleural cavity. Childhood empyema is an important complication of bacterial pneumonia. The incidence of empyema is increasing worldwide. Despite being recognized since the ancient times, the appropriate management of paediatric empyema thoracis remains controversial. Aims \& objectives: 50 patients were included in the age group of less than 12 years with the diagnosis of empyema. All the patients were analysed for the clinical course of the disease, radiological investigations, pleural fluid biochemical and microbiological parameters, and various treatment options. Short term follow up was done for complications and sequelae. Subjects and Methods: 64\% of the children were under 4 years of age. Males outnumbered females with a ratio of 1.17:1. 74\% of the cases were recorded during spring and early summer. $64 \%$ of the cases belonged to lower socioeconomic strata. Fever, cough and hurried respiration were the predominant symptoms and the duration of illness of $80 \%$ of the cases was 7 - 14 days. $64 \%$ of our patients had received antibiotics prior to admission. Pneumonia predisposed to empyema in $48 \%$ of the cases. $56 \%$ of the cases had protein energy malnutrition and $2 \%$ were severely malnourished. Left sided empyemas (54\%) were more frequent than the right (46\%). $46 \%$ of the patients had culture positivity on pleural fluid. The commonest organism isolated was staphylococcus aureus (18\%). Conclusion: Management of primary empyema continues to be controversial in terms of duration of antibiotic therapy and the indications for and timing of surgery.

Keywords: Empyema, Children, Pneumonia, Intercostal drainage, Intrapleural streptokinase.

Corresponding Author: Dr. Sudhakar Hegade, Assistant Professor, Department of Pediatrics, VIMS, Ballari, Karnataka.

Received: September 2019

Accepted: September 2019

\section{Introduction}

An empyema thoracis is simply a collection of pus in the pleural space. Many term a parapneumonic effusion associated with bacterial pneumonia, lung abscess, or bronchiectasis an empyema whereas others state that only parapneumonic effusions with positive pleural fluid cultures can be called an empyema. Likewise, others use the term 'complicated parapneumonic effusion' to refer to those effusions that do not resolve without tube thoracostomy.

Steven J. Hoff et al have defined empyema as pleural fluid demonstrated on chest radiograph that contained $>1,000$ white blood cells/mm3 or from which organisms could be cultured, whereas F. Jones McLaughlin et al have defined empyema as either frank pus on thoracocentesis or pleural fluid with WBC count $>1500 / \mathrm{mm} 3$, a positive Gram stain and/or culture. ${ }^{[1]}$

The pleural circulation is finely balanced by secretion and absorption of pleural fluid by lymphatic drainage. When this balance is disturbed by infection, pleural fluid will accumulate. Infection results in pleural inflammation with increased vascular permeability, and an influx of bacteria and inflammatory cells such as neutrophils. This inflammatory cascade is further increased by cytokine release from mesothelial cells. Activation of the coagulation cascade leads to decreased fibrinolysis and the deposition of fibrin, which causes the classic loculations and peel formation seen in later stages. ${ }^{2]}$

If empyema occurs in the setting of underlying suppurative lung disease (ie. Pneumonia, lung abcess, or bronchiectasis) it is referred to as a parapneumonic empyema (60\%cases). Other causes of thoracic empyema are surgery $(20 \%)$, trauma(10\%), oesophageal rupture, other chest wall or mediastenal infections, bronchopleural fistulae, extension of subphrenic or hepatic abcess, instrumentation of pleural spaces and rarely hematogenous seeding from a distant site of infection.

The ongoing inflammatory process leads to a mediatorinduced increased permeability of local tissue and of regional capillaries. The subsequent accumulation of fluid in the pleural space is probably the combined result of the influx of pulmonary interstitial fluid and of a local microvascular exudate. The fluid is usually clear and sterile, with low viscosity, white blood cell count, the $\mathrm{pH}$ is normal and the lactate dehydrogenate (LDH) activity is $<500$ 
international units. ${ }^{[3]}$

Transitional Fibrino purulent Stagemay develop quickly (within hours) in patients who are not receiving antibiotics, or who are treated with ineffective antibiotics. It is characterized by the deposition of fibrin clots and fibrin membranes ("sails") in the pleural space, which lead to loculations with increasing numbers of isolated collections of fluid. It is usually accompanied by (and caused by) bacterial invasion from the pulmonary parenchyma. The fluid is often turbid or frank pus. Cytology shows neutrophils and often degenerated cells, and Gram stains and bacterial cultures are usually positive. The metabolic and cytolytical activity in these effusions is high, as reflected by low $\mathrm{pH}$ values $(<7.2)$, and high $\mathrm{LDH}$ activities (often $>1,000$ IU). Chronic organizing stage is characterized by the invasion of fibroblasts, leading to the transformation of interpleural fibrin membranes into a web of thick and nonelastic pleural peels. Functionally, gas exchange is often severely impaired on the side of the organizing empyema ("trapped lung"). It is charecterised by pleural fluid glucose $<40 \mathrm{mg} / \mathrm{dl}$, and a PH $<7.0$. The further course may vary from spontaneous healing with persistent defects of lung function to chronic forms of empyema with high risks for further complications, such as bronchopleural fistula, discharging sinus, lung abscess, or "empyema necessitans" (spontaneous perforation through the chest wall). ${ }^{[4]}$

In a previously well child, pleural effusions are usually secondary to acute bacterial pneumonia and less often due to chronic infections such as pulmonary tuberculosis. When associated with infection, effusions are usually unilateral and bilateral empyemas are unusual. Bilateral effusions may indicate tuberculosis or a parasitic infection. The prevalence of small parapneumonic effusions is difficult to estimate (and often undetected), and they are unlikely to be reported in case series. Other infections such as lung abscess and chronic suppurative conditions such as bronchiectasis may also produce pleural effusion. Predisposing causes include immunedeficiencies, aspiration, post-surgery and trauma. ${ }^{[5]}$ Pleural effusions are not always secondary to infection and may be genuinely sterile. Rarely, an effusion is the presenting sign of an underlying malignancy in a child who was well before the symptoms related to the effusion. Many of the other secondary causes of pleural effusion will be in children with a known underlying condition such as congenital heart disease, renal disease, connective tissue disorders, and trauma which includes post-cardiothoracic surgery.

The reported rate of identifying an infectious organism from pleural fluid varies markedly, from $8 \%$ to $76 \%$. In the preantibiotic era, Streptococcus pneumoniae was the major pathogen recovered from pleural fluid, followed by betahaemolytic streptococci (probably Streptococcus pyogenes) and Staphylococcus aureus. With the introduction of Sulphonamides and then penicillin, the incidence of $\mathrm{S}$ pneumoniae and $\mathrm{S}$ pyogenes was markedly reduced and the relative proportion of Staphylococcus aureus increased, especially in the late 1950s as the rate of penicillin resistant $\mathrm{S}$ aureus began to increase.

Pneumococcal infection remains the most common cause in the developed world, and Staphylococcus aureus continues to be the most common organism isolated in children from South Asia.

Staphylococcus aureus was particularly evident in the first 6 months of life, and accounted for $29 \%$ to $63 \%$ of cases. There have also been reports of empyema due to methicillinresistant Staph. aureus in children. Following the introduction of penicillinase stable penicillins and other anti staphylococcal agents, the relative proportion of empyema due to S. pneumoniae has increased once more. Currently it seems to be emerging as the predominant pathogen in childhood empyema, although this is not always reflected in culture results as many are culture negative. Nevertheless, $S$ pneumoniae was the principal organism in three recent case series from the USA, and the majority of culture negative cases in two UK series have been shown to be $S$ pneumoniae by molecular techniques ${ }^{[6]}$

The bacterial aetiological profile differs in developing countries with $\mathrm{S}$ aureus being the predominant pathogen, especially during the hot and humid months when staphylococcal skin infections are more prevalent. There has been a decline in culture positive $\mathrm{S}$ pneumoniae, probably because of prior antibiotic use. Various Gram negative organisms for example, Enterobacteriaceae such as Klebsiellaspp and Pseudomonas aeruginosa are also more common than in the UK; they are not limited to infants and may be associated with protein energy malnutrition. ${ }^{[6]}$

\section{Subjects and Methods}

\section{$\underline{\text { Sample Size }}$}

50 children in the age group less than twelve (12) years who were admitted with the diagnosis of empyema were included in the study.

\section{Inclusion Criteria}

Children in the age group less than 12 years with the diagnosis of empyema, (frank pus on thoracocentesis) were included in the study.

Diagnosis was based on history, clinical examination, supported further by the evidence of chest x-ray, ultrasonography, computed tomography scan (wherever feasible)and diagnostic thoracocentesis.

\section{Exclusion Criteria}

1. Patients not willing to be included in study group

2. Post surgical empyema

3. Post-traumatic empyema

4. children with age group more than 12years.

50 suspected cases of empyema after admission had a detailed history taking as per the proforma, with emphasis on duration of symptoms, previous medication, contact history of tuberculosis and course of illness before admission. 


\section{Hegade \& Biradar; The Clinical and Bacterialagical Prafile of Children with Empyema in a Jertiary Haspital}

Results

Table 1: Age distribution of empyema in children $(n=50)$

\begin{tabular}{|l|l|l|}
\hline Age in years & No. of Patients & \% \\
\hline$<1$ year & 3 & 6 \\
\hline $1-4$ years & 31 & 62 \\
\hline $5-9$ years & 14 & 28 \\
\hline $10-12$ years & 2 & 4 \\
\hline Total & 50 & 100.0 \\
\hline
\end{tabular}

$31 / 50(62 \%)$ of affected patients were between 1 to 4 years. $3(6 \%)$ caseswere seen in infancy. Youngest child was 1 months old and the oldest was 12 years old.

Table 2: Gender distribution $(\mathbf{n}=50)$

\begin{tabular}{|l|l|l|}
\hline Gender & No. of cases & \% \\
\hline Male & 27 & 54 \\
\hline Female & 23 & 46 \\
\hline Total & 50 & 100.0 \\
\hline
\end{tabular}

$27 / 50$ were males and 23/50 were females. Male to female ratio was $1.17: 1$.

\begin{tabular}{|c|c|c|}
\hline Clinical presentation & Number $(n=50)$ & $\%$ \\
\hline Fever & 50 & 100 \\
\hline Cough & 41 & 82 \\
\hline Hurried Breathing & 39 & 78 \\
\hline Sputum production & 24 & 48 \\
\hline
\end{tabular}

All patients had fever. Cough and hurried breathing was seen in $41 / 50(82 \%)$ and $39 / 50(78 \%)$ cases respectively. Sputum production was seen in $24 / 50(48 \%)$ cases. Fever was the predominant symptom in 30 cases $(60 \%)$ and cough in 10 cases $(20 \%)$.

Table 4: Duration of symptoms

\begin{tabular}{|l|l|l|}
\hline Duration of symptoms & No. of Patients $(\mathbf{n}=\mathbf{5 0})$ & $\mathbf{\%}$ \\
\hline$<4$ days & 2 & 4 \\
\hline $5-14$ & 40 & 80 \\
\hline$>15$ & 8 & 16 \\
\hline Total & 50 & 100.0 \\
\hline
\end{tabular}

Mean duration of the symptoms was 10 days. 40/50 cases presented with in 5-14 days of symptoms(80\%) and 8/50 cases after 15 days of symptoms(16\%). Maximum cases presented in stage 2( Transitionalfibrino purulent stage).

\section{Table 5: Predisposing factors}

\begin{tabular}{|l|l|l|}
\hline Predisposing Factors & No. of Patients $(\mathbf{n}=\mathbf{5 0})$ & \% \\
\hline Pneumonia & 24 & 48 \\
\hline Tuberculosis & 9 & 18 \\
\hline Exanthematous Fever & 2 & 4 \\
\hline No predisposing factors & 15 & 30 \\
\hline Total & 50 & 100.0 \\
\hline
\end{tabular}

In the present study, pneumonia predisposed to $24 / 50(48 \%)$ of the empyema cases. There was history of measles in 2 cases(4\%) and contact with tuberculosis in 9 cases(18\%).
Table 6: Presence of pallor

\begin{tabular}{|l|l|l|}
\hline Pallor & No. of patients $(\mathbf{n}=\mathbf{5 0})$ & $\mathbf{\%}$ \\
\hline Yes & 22 & 44 \\
\hline No & 28 & 56 \\
\hline Total & 50 & 100.0 \\
\hline
\end{tabular}

$22 / 50(44 \%)$ had pallor at the time of admission.

Table 7: Weight and Incidence of PEM ( IAP Classification)

\begin{tabular}{|l|l|l|}
\hline Weight/PEM & No. of Patients $(\mathbf{n}=\mathbf{5 0})$ & \% \\
\hline Weight $(\mathrm{kg})$ & & \\
\hline $5-10$ & 24 & 48 \\
\hline $11-15$ & 17 & 34 \\
\hline $16-20$ & 6 & 12 \\
\hline$>20$ & 3 & 6 \\
\hline PEM & & \\
\hline NO & 22 & 44 \\
\hline 1 & 13 & 26 \\
\hline 2 & 8 & 16 \\
\hline 3 & 6 & 12 \\
\hline 4 & 1 & 2 \\
\hline TOTAL & 50 & 100.0 \\
\hline
\end{tabular}

28/50 (56\%) had PEM according to IAP classification. $13 / 50(26 \%)$ had grade 1 PEM and 8/50(16\%) had grade II PEM.

Table 8: Respiratory findings

\begin{tabular}{|l|l|l|}
\hline Respiratory Findings & No. of Patients $(\mathbf{n}=\mathbf{5 0})$ & \% \\
\hline Reduced air entry & 50 & 100 \\
\hline Dullness & 50 & 100 \\
\hline Mediastenal shift & 15 & 30 \\
\hline
\end{tabular}

All patients had reduced air entry on the respective side and dullness on percussion. $15 / 50(30 \%)$ had mediastinal shift.

Table 9: Diagnosis - Side affected

\begin{tabular}{|l|l|l|}
\hline Diagnosis & No. of Patients $(\mathbf{n = 5 0})$ & \% \\
\hline Right & 23 & 46 \\
\hline Left & 27 & 54 \\
\hline Total & 50 & 100.0 \\
\hline
\end{tabular}

Empyema occurred more frequently on the left side $27(54 \%)$ than the right 23(46\%). Bilateral empyemas were not seen in the present study.

Table 10: Bacteriological profile in empyema

\begin{tabular}{|l|l|l|}
\hline Bacteriological Pattern & No. of Patients $(\mathbf{n = 5 0})$ & \% \\
\hline No Growth & 27 & 54 \\
\hline Growth & 23 & 46 \\
\hline Staphylococcus aureus & 9 & 18 \\
\hline Streptococcus Pneumoniae & 6 & 12 \\
\hline Klebsiella & 2 & 4 \\
\hline Citrobacter & 4 & 8 \\
\hline PseudominasAeuroginosa & 2 & 4 \\
\hline Total & 50 & 100.0 \\
\hline
\end{tabular}

Bacteriological isolation was seen in 23/50 (46\%) of all the patients of empyema. Staphylococcus aureus was isolated in 9/23 (18\%) of all patients, followed by Streptococcus pneumonia in $6 / 23$ cases $(12 \%)$. Klebsiella and pseudomonas species with $2 / 23(4 \%)$. 


\section{Hegade \& Biradar; The Clinical and Bacterialagical Profile of Children with Empyema in a Tertiary Haspital}

\section{Discussion}

The age incidence has undergone a change over the years. Pre-antibiotic era had a higher group of affected infants while later years showing increased affection of pre school children.

In the present study, 31(62\%) patients were between 1 to 4 years and 3(6\%)were infants. Gerald et al and Baranwal AK et al reported similar incidence. Langley et al M however found 3 to 5 years to be the commonly affected group. The higher incidence in children aged 1 to 4 years can be partly explained due to the increased susceptibility to staphylococcal and streptococcal pneumonia, which are the common cause of empyema.

Childhood Empyema has been found to be more common in males. Many past series also reported their predominance. Present study also showed male preponderance of 1.17:1.

Table 11: Comparison of sex incidence

\begin{tabular}{|l|l|l|l|}
\hline $\begin{array}{l}\text { Baranwal } \\
\text { AK et } \mathbf{a l}^{[\mathbf{7 0 ]}}\end{array}$ & $\begin{array}{l}\text { Easthem et } \\
\mathbf{a}^{[\mathbf{7}]}\end{array}$ & $\begin{array}{l}\text { Langley M et } \\
\mathbf{a}^{[\mathbf{8}]}\end{array}$ & Present study \\
\hline 2003 & 2004 & 2008 & $2016-2018$ \\
\hline $\mathrm{M}: \mathrm{F}(2.4: 1)$ & $\mathrm{M}: \mathrm{F}(2.3: 1)$ & $\mathrm{M}: \mathrm{F}(1.04: 1)$ & $\mathrm{M}: \mathrm{F}(1.17: 1)$ \\
\hline
\end{tabular}

Varied opinions regarding the seasonal prevalence of childhood empyema was noted in the past series.

\begin{tabular}{|l|l|l|l|}
\hline Table 12: Comparison of seasonal variation \\
\begin{tabular}{|l} 
Baranwal AK \\
et al ${ }^{[\mathbf{9}]}$
\end{tabular} & Barnes et al ${ }^{[\mathbf{1 0}]}$ & $\begin{array}{l}\text { Langley M et } \\
\mathbf{a}^{\mathbf{[ 8 ]}}\end{array}$ & Present study \\
\hline 2003 & 2005 & 2008 & $2016-2018$ \\
\hline May to August & Oct- Dec & Nov - April & Jan-Mar \\
\hline Summer & Winter & Spring & Spring \\
\hline
\end{tabular}

In the present study $37(74 \%)$ of them presented in the months of January to June accounting for majority occurring in the spring and early summer. Only $6(12 \%)$ presented in the months of July to september. Few earlier studies have reported most cases in winter and early spring, probably due to the increased spread of infections due to overcrowding, ill ventilation, chilling breeze and soaking rain.

The classical picture of a child with empyema used to be that of a very sick, breathless child, running high fever and looking toxic presenting late in fibrinopurulent stage.

The commonest symptoms were fever in $50(100 \%)$, cough in $41(82 \%)$ and hurried respiration in $39(78 \%)$ of the patients, sputum production in $24(48 \%)$ of the cases.

Table 13: Comparison of clinical presentation

\begin{tabular}{|l|l|l|l|}
\hline Symptoms & Gun F et al $^{[\mathbf{1 1}]}$ & $\begin{array}{l}\text { Kosar A et } \\
\mathbf{a}^{[\mathbf{1 2}]}\end{array}$ & Present study \\
\hline & 2007 & 2008 & $2016-2018$ \\
\hline Fever & $72 / 79(92 \%)$ & $97 / 111(87 \%)$ & $50 / 50(100 \%)$ \\
\hline Cough & $70 / 79(88 \%)$ & $88 / 111(79 \%)$ & $41 / 50(82 \%)$ \\
\hline $\begin{array}{l}\text { Hurried } \\
\text { breathing }\end{array}$ & $51 / 79(64 \%)$ & $65 / 111(58 \%)$ & $39 / 50(78 \%)$ \\
\hline
\end{tabular}

Thus, although there appears to be some tachypnea, respiratory distress in the form of alaenasi flaring, intercostal and subcostal retractions have not been prominently observed in the recent series. Pain abdomen was common in staphylococcal empyema; Chan et al 1993 also has expressed similar views. 1/40 (2.5\%) had symptoms like oliguria, altered sensorium and presented with septic shock at presentation.

The absence of frank breathlessness may be due to prior treatment with antibiotics. Antibiotic administration prior to the referral to a tertiary hospital was observed by Khanna SK as one of the factors leading to chronicity.

In the present study, Pneumonia predisposed to $24 / 50(48 \%)$ of empyemas, Many of the past studies reported measles as common predisposing factor, in the present series 2 cases(4\%) had exanthematous illnesses. 9(18\%) cases had history of tuberculosis.

Table 14: Comparison of predisposing factors

\begin{tabular}{|l|l|l|}
\hline Disease & Baranwal AK et al $^{[\mathbf{9 ]}}$ & Present study $^{-}$ \\
\hline & 2003 & 2008 \\
\hline Pneumonia & $205 / 243(84.3 \%)$ & $24 / 50(48 \%)$ \\
\hline Exanthematous fever & $3 / 243(1.23 \%)$ & $2 / 50(4 \%)$ \\
\hline Tuberculosis & - & $9 / 50(18 \%)$ \\
\hline
\end{tabular}

In the present study, $40(80 \%)$ had presented with history of symptoms for more than 1 week with an average of 10 days and 32/50(64\%) had taken antibiotics earlier. Other factors leading to chronicity are delayed medical attention, improper use of antibiotics, inadequate dosage. Average duration of symptoms in the study done by Eastham et al (2004) was 5 days (0-25 days).

Table 15: Comparison of duration of symptoms

\begin{tabular}{|l|l|l|}
\hline Eastham et a $^{[\mathbf{7 ]}}$ & ${\text { Barnes et } \mathbf{a l}^{[\mathbf{1 0 ]}}}^{{ }^{[}}$ & Present study \\
\hline 2004 & 2005 & $2016-2018$ \\
\hline 5 days & 11 days & 10 days \\
\hline
\end{tabular}

\section{Conclusion}

Empyema continues to be prevalent in our country particularly in the lower socioeconomic strata due to the delay in seeking medical care, inappropriate antibiotics and dosages and duration of antibiotic treatment.

Indiscriminate use of antibiotics might have increased the overgrowth of multi resistant organisms, there on leading to chronicity and morbidity of empyema.

Empyema fluid is diagnostic for pathogens if appropriate handling and early cultures but in the present scenario with prior antibiotic treatment, the fluid is sterile most of the times. Pleural fluid biochemical parameters would also vary depending on the stage of empyema, severity and previous antibiotic therapy.Staphylococcus aureus was the commonest organism isolated as compared to the other studies and majority of them responded to antibiotics. It is ideal to start an antibiotic with good staphylococcal coverage at admission in infants with empyema. 


\section{Hegade \& Biradar; The Clinical and Bacterialagical Profile of Children with Empyema in a Tertiary Haspital}

\section{References}

1. Miserocchi G. Physiology and pathophysiology of pleural fluid turnover. European Respiratory Journal 1997; 10: 219-225.

2. Mutsaers SE. Mesothelial cells: their structure, function and role in serosal repair. Respirology 2002; 7: 171-191.

3. Peng MJ and Wang NS. Embryology and gross structure. In: Light RW and Lee YCG (eds.) Textbook of Pleural Disease. 2003; pp. 3-17. Arnold publishers

4. Sahn SA. State of the art: the pleura. American Review of Respiratory Diseases 1988; 138: 184-231.

5. Wang NS. Anatomy of the pleura. Clinics in Chest Medicine 1998; 19: 229-240.

6. Jaffe A and Balfour-Lynn IM. Management of Empyema in Children. Pediatric Pulmonology 2005; 40:148-156.

7. Eastham KM, Freeman R, Kearns AM et al. Clinical features, etiology and outcome of empyema in children in the north east of England. Thorax 2004; 59: 522-525.

8. Langley MJ, Kellner JD, Solomon $\mathrm{N}$ et al. Empyema associated with
9. community-acquired pneumonia: A Pediatric Investigator's Collaborative Network on Infections in Canada (PICNIC) study. BMC Infectious Diseases 2008, 8: 129.

10. Baranwal AK, Singh M, Marwaha RK. Empyema thoracis: a 10-year comparative review of hospitalised children from south Asia. Arch Dis Child 2003; 88: 1009-1014.

11. Barnes NP, Hull J, Thomson AH. Medical Management of Parapneumonic Pleural Disease. Pediatric Pulmonology 2005; 39: 127134.

12. Gün F, Salman T, Abbasoglu L et al. Early Decortication in Childhood Empyema Thoracis. ActaChirbelg 2007; 107: 225-227.

13. Kosar A, Demirhan R, Sancakli et al. Management of PostpneumonicEmpyemas in Children. ActaChirBelg 2008; 108: 208211.

Copyright: (C) the author(s), 2019. It is an open-access article distributed under the terms of the Creative Commons Attribution License (CC BY 4.0), which permits authors to retain ownership of the copyright for their content, and allow anyone to download, reuse, reprint, modify, distribute and/or copy the content as long as the original authors and source are cited.

How to cite this article: Hegade S, Biradar S. The Clinical and Bacteriological Profile of Children with Empyema in a Tertiary Hospital. Asian J. Clin.Pediatr.Neonatol.2019;7(3):49-53.

DOI: dx.doi.org/10.21276/ajcpn.2019.7.3.13

Source of Support: Nil, Conflict of Interest: None declared. 